\title{
Análise crítica do processo de auditoria de sistema de gestão da qualidade no setor aeroespacial
}

\section{Critical analisys of quality management system audit conducted with in aerospace industries}

\author{
Luciano Pereira de Souza ${ }^{1}$ \\ Antonio Faria Neto ${ }^{2,3}$ \\ Jorge Muniz Jr. ${ }^{4}$
}

\begin{abstract}
Resumo: A auditoria de sistema de gestão da qualidade é utilizada pelas organizações para melhorar o seu desempenho por meio de avaliações sistemáticas dos processos. Ao mesmo tempo, a atividade de auditoria vem sendo questionada quanto à sua capacidade de promover essa melhoria. Diante deste cenário, este artigo objetiva analisar fatores que afetam o processo de auditoria de certificação do sistema de gestão da qualidade, de modo a indicar oportunidades de melhoria das auditorias. A pesquisa é delimitada a auditorias no setor aeroespacial, que são orientadas pela NBR 15100. Foi realizada uma survey com auditores experientes nos anos de 2009 e 2010. São identificados fatores como comunicação, seleção da equipe, conhecimento do setor e os resultados mostram a existência de discrepâncias consideráveis entre o nível de "importância" e de "aplicação" desses fatores nas organizações auditadas.
\end{abstract}

Palavras-chave: Sistema de gestão da qualidade. Certificação. Auditoria. Setor aerospacial. NBR 15100.

\begin{abstract}
The audit of the quality management system is used by organizations to improve their performance through systematic evaluations of the processes. At the same time, the traditional audit system has been questioned about its ability to promote such improvement. Hence, this paper aims to analyze factors that affect the audit process for certification of quality management system to indicate opportunities for audit improvement. This research focuses on audits conducted within the aerospace sector based on the NBR 15100. A survey of experienced auditors was conducted in the years of 2009 and 2010. Some factors were identified (e.g. communication, team selection, industry expertise) and the results show that there are considerable discrepancies between the level of "importance" and "implementation" of those factors in the organizations audited.
\end{abstract}

Keywords: Quality management system. Certification. Audit. Aerospace industry. NBR 15100.

\section{Introdução}

A busca por certificações em conformidade com a ISO 9001 e com as normas específicas de setores industriais vem crescendo ao longo dos anos. Ao final de dezembro de 2008, quase um milhão de certificados ISO 9001 tinham sido emitidos em 176 países em todo o mundo (INTERNATIONAL..., 2008).

A auditoria de Sistema de Gestão de Qualidade (SGQ) é uma etapa fundamental do processo de certificação. Ela é usada para monitorar e avaliar a eficácia do sistema, identificar oportunidades de melhorias e diminuir, assim, os riscos associados à sobrevivência das organizações. Poksinska et al. (2006) mostram que a auditoria de certificação pode ser uma ferramenta para garantir a eficácia e a melhoria contínua do SGQ. No entanto, estes mesmos autores citam que muitas organizações ainda não reconhecem as oportunidades de melhorias que as auditorias externas podem fornecer.

Apesar do processo de auditoria, quando bem realizado, trazer benefícios para a gestão de uma organização, tanto em nível operacional quanto estratégico, a palavra "auditoria" nunca esteve

\footnotetext{
${ }^{1}$ Instituto de Fomento e Coordenação Industrial - IFI, Programa de Pós-Graduação em Engenharia Mecânica, Universidade de Taubaté - UNITAU, Rua Daniel Danelli, sn, Jardim Morumbi, CEP 12060-440, Taubaté, SP, Brasil, e-mail: lucianolps@ifi.cta.br

2 Instituto Básico de Exatas, Programa de Mestrado Profissional em Engenharia Mecânica,

Universidade de Taubaté - UNITAU, Rua Daniel Danelli, sn, Jardim Morumbi, CEP 12060-440, Taubaté, SP, Brasil, e-mail: antfarianeto@gmail.com

${ }^{3}$ Universidade Estadual Paulista - UNESP, Av. Ariberto Pereira da Cunha, 333, Portal das Colinas, CEP 12516-410, Guaratinguetá, SP, Brasil

${ }^{4}$ Departamento de Produção, Universidade Estadual Paulista - UNESP, Av. Ariberto Pereira da Cunha, 333, Portal das Colinas, CEP 12516-410, Guaratinguetá, SP, Brasil, e-mail: jorgemuniz@ feg.unesp.br
}

Recebido em 29/4/2011 — Aceito em 19/11/2011

Suporte financeiro: Agencia Espacial Brasileira (AEB). 
acompanhada de uma conotação amplamente positiva, e este processo sofre críticas (BECKMERHAGEN et al., 2004).

Para Kaziliûnas (2008), a principal razão para conduzir auditorias é obter informações efetivas que servem como entradas para tomadas de decisões gerenciais, mas a vasta maioria dos auditores apenas produz dados para conceder um certificado, para melhorar documentação ou reforçar conformidade.

Ainda segundo Kaziliûnas (2008), existem diversas abordagens utilizadas para conduzir auditorias internas e externas de sistemas de gestão, mas nem todas elas são eficazes, quer por deficiência da abordagem, quer por deficiências dos auditores, como por exemplo, a falta de habilidades interpessoais ou experiência para envolver-se eficientemente tanto com o grupo de diretores quanto com os trabalhadores no chão de fábrica.

É fato que por si só a auditoria da qualidade não garante a qualidade dos produtos e serviços, mas é inegável a sua contribuição neste sentido, uma vez que as medidas para promover melhorias são baseadas em fatos provenientes da auditoria da qualidade. Várias organizações procuram saber como melhorar as auditorias da qualidade, frequentemente ineficientes e demoradas, e como descobrir o valor que ela agrega (PISKAR, 2006).

Desta forma, ao mesmo tempo que a auditoria vem mostrando a sua importância para o aumento da competitividade das organizações, também fica evidente a existência de problemas e a necessidade de melhorias deste processo, conforme afirma Piskar (2006). Afinal, quais são os fatores que afetam o processo da auditoria? Onde estão os principais problemas, ou as maiores oportunidades de melhorias deste processo, e como estes fatores estão sendo aplicados, na prática, ao se realizar a auditoria? Estas questões orientam a pesquisa apresentada no presente artigo.

Este artigo tem como objetivo principal analisar o processo de auditoria de certificação de sistema de gestão da qualidade no setor aeroespacial brasileiro, de modo a identificar oportunidades de melhoria neste processo, por meio da perspectiva dos auditores da qualidade da cadeia aeroespacial brasileira.

$\mathrm{O}$ atendimento do objetivo principal envolve o seu desdobramento e detalhamento em três objetivos específicos:

- Identificar os principais fatores que afetam o processo de auditoria de sistema de gestão da qualidade no setor aeroespacial;

- Avaliar a percepção dos auditores da qualidade do setor aeroespacial quanto aos níveis de importância e de aplicação dos fatores que afetam o processo de auditoria de sistema de gestão da qualidade deste setor;
- Analisar a relação existente entre a percepção dos auditores quanto ao nível de importância dos fatores e quanto ao nível de aplicação destes fatores na prática.

Este trabalho limita-se às auditorias de certificação de sistema de gestão da qualidade no setor aeroespacial brasileiro. Os auditores que participaram da pesquisa são auditores em atividade no Brasil, que realizam auditorias com base na norma de SGQ do setor aeroespacial (NBR 15100 ou AS 9100) e que atendem aos requisitos de qualificação determinados pelo Instituto Nacional de Metrologia, Normalização e Qualidade Industrial (INMETRO) e pelo International Aerospace Quality Group (IAQG).

Embora os estudos venham mostrando a importância da auditoria de SGQ como uma ferramenta para a gestão das organizações, também identificam diversos problemas com relação a este processo. A identificação e análise dos principais fatores que afetam a auditoria de certificação de sistema de gestão da qualidade no setor aeroespacial é uma oportunidade de se identificar quais são e onde se encontram os problemas relacionados com a auditoria da qualidade neste setor.

Indiretamente, toda a cadeia de certificação aeroespacial pode se beneficiar com a melhoria no processo de auditoria de certificação, iniciando pelo organismo de acreditação, por meio de estabelecimento de requisitos que atuem sobre os problemas da auditoria. As organizações certificadas também se beneficiam, pois podem melhorar a eficácia de seu sistema de gestão e aumentar o reconhecimento de seu cliente, tornando-se mais competitiva. Até mesmo os clientes finais se beneficiam das melhorias do processo de auditoria de certificação de SGQ, pois poderão estar mais satisfeitos com os produtos e serviços adquiridos.

\section{Aspectos relacionados à norma NBR 15100}

A certificação de sistemas de gestão pode ser definida como uma atestação, por terceira parte, de que $\mathrm{o}$ atendimento aos requisitos especificados para sistemas de gestão foi demonstrado (NBR ISO/IEC 17000) (ASSOCIAÇÃO..., 2005). A certificação deve ser considerada como uma forma de comunicar credibilidade aos clientes (TERLAACK; KING, 2006).

O processo de certificação favorece a inclusão de indicadores de desempenho que auxiliam nas tomadas de decisão e no planejamento de ações corretivas, além de permitir um maior controle de documentos (MIRANDA et al.,2006). Wiele et al. (2004) sugerem que as organizações buscam o certificado sob pressão externa (clientes, governo ou matriz) e a possível causa para elas relutarem em buscar a certificação por iniciativa própria pode ser o ceticismo quanto 
às contribuições das normas e certificações para a melhoria do desempenho econômico do negócio.

A atividade de acreditação pode ser definida como

[...] atestação de terceira parte relacionada a um organismo de avaliação da conformidade, comunicando a demonstração formal da sua competência para realizar tarefas específicas de avaliação da conformidade. (NBR ISO/IEC 17000) (ASSOCIAÇÃO..., 2005, p. 5).

Para Costa (2006), a acreditação pode ser entendida como o reconhecimento formal de que um organismo de certificação atende a requisitos previamente definidos e demonstra competência para realizar suas atividades com confiança.

A NBR ISO/IEC 17021 (ASSOCIAÇÃO..., 2007) estabelece os requisitos para organismos de certificação de sistemas de gestão.

O Conselho do IAQG é composto por vinte e seis representantes provenientes dos três setores. Dez representantes das Américas, dez da Europa e seis da Ásia-Pacífico. Este Conselho tem responsabilidade por (INTERNATIONAL ..., 2010):

- Agir sempre nos melhores interesses das companhias membros do IAQG como um todo ao invés de um setor ou companhia específicos;

- Definir a direção, proposta e objetivos do IAQG;

- Garantir que os requisitos do IAQG sejam implementados;

- Garantir que as iniciativas propostas sejam desenvolvidas e submetidas para a aprovação do Conselho para se alcançar os objetivos do IAQG;

- Analisar criticamente, aprovar ou rejeitar as iniciativas propostas pelo Grupo Estratégico de Trabalho e garantir que os recursos estejam disponíveis para permitir a implementação com sucesso;

- Garantir comunicação efetiva para e com a Assembleia Geral, Associações Comerciais, Autoridades Nacionais e Governos.

Vale lembrar que a NBR 15100 é tecnicamente equivalente à AS 9100. Na prática, é a tradução para o português da norma americana, realizada pela Associação Brasileira de Normas Técnicas (ABNT).

A certificação SGQ de uma organização consiste em um processo cíclico, conforme a NBR ISO/ IEC 17021 (ASSOCIAÇÃO..., 2007), e inclui uma auditoria inicial, auditorias de supervisão no primeiro e no segundo ano, e uma auditoria de recertificação antes do vencimento do certificado, que tem validade de três anos.

A norma NBR ISO 19011 (ASSOCIAÇÃO..., 2002) identifica os cinco princípios da auditoria, que fazem dela uma ferramenta eficaz e confiável, e fornece informações sobre as quais uma organização pode agir para melhorar seu desempenho. Ainda segundo esta norma, a aderência a estes princípios é um pré-requisito para se fornecer conclusões de auditoria que são relevantes e suficientes, e para permitir que auditores, mesmo trabalhando independentemente entre si, cheguem a conclusões semelhantes em circunstâncias semelhantes. Os três primeiros princípios a seguir estão relacionados a auditores, enquanto que os dois seguintes estão relacionados à auditoria. Estes princípios são:

- Conduta ética: o fundamento do profissionalismo; [...] Confiança, integridade, confidencialidade e discrição são essenciais para auditar. (ASSOCIAÇÃO..., 2002, p. 4);

- Apresentação justa: a obrigação de reportar com veracidade e exatidão:

Constatações de auditoria, conclusões de auditoria e relatórios de auditoria refletem verdadeiramente e com precisão as atividades de auditoria. Obstáculos significantes encontrados durante a auditoria e opiniões divergentes não resolvidas entre a equipe de auditoria e $\mathrm{o}$ auditado são relatados. (ASSOCIAÇÃO..., 2002, p. 4);

- Devido cuidado profissional: a aplicação de diligência e julgamento na auditoria:

Cuidado necessário devido à importância da tarefa que eles executam e a confiança colocada neles pelos clientes de auditoria e outras partes interessadas. Ter a competência necessária é um fator importante. (ASSOCIAÇÃO..., 2002, p. 4);

- Independência: a base para a imparcialidade da auditoria e objetividade nas conclusões da auditoria:

Auditores são independentes da atividade a ser auditada e são livres de tendência e conflito de interesse. Auditores mantêm um estado de mente aberta ao longo do processo de auditoria para assegurar que as constatações e conclusões da auditoria sejam baseadas somente nas evidências da auditoria. (ASSOCIAÇÃO..., 2002, p. 4);

- Abordagem baseada em evidência: o método racional para alcançar conclusões de auditoria confiáveis e reproduzíveis em um processo sistemático de auditoria:

Evidência de auditoria é verificável. É baseada em amostras de informações disponíveis, uma vez que uma auditoria é realizada durante um período de tempo finito e com recursos finitos. $\mathrm{O}$ uso apropriado de amostragem está intimamente ligado à confiança que pode ser colocada nas conclusões de auditoria. (ASSOCIAÇÃO..., 2002, p. 4). 
Segundo Russell (2007), a contínua análise crítica destes princípios mantém os auditores no caminho certo e ajuda a garantir a eficácia das auditorias. A competência de auditores de SGQ do setor aeroespacial é alcançada por meio de uma combinação de experiência e treinamento em auditorias, treinamento específico na indústria e experiência de trabalho no setor aeroespacial (INSTITUTO..., 2010).

Os auditores de SGQ do setor aeroespacial que atuam em auditorias de certificação são divididos em dois grupos, conforme a sua qualificação: Auditores NBR 15100 com experiência aeroespacial, chamados de AEA (Aerospace Experienced Auditor), e Auditores NBR 15100.

O primeiro grupo, auditores AEA, é composto por auditores com competência para atuar como líderes de equipe de auditoria, ou auditor-líder, do setor aeroespacial, enquanto o segundo grupo, auditores NBR 15100, é composto por auditores do setor aeroespacial, mas que ainda não possuem as competências necessárias para atuar como líderes de equipe de auditoria.

\section{Procedimento metodológico}

Esta pesquisa foi realizada entre os anos de 2009-2010. Inicialmente fez-se uma revisão da literatura em busca de fatores apontados como relevantes para o sucesso de uma auditoria.

Em seguida, realizou-se uma pesquisa com os auditores do setor aeroespacial, por meio da aplicação de um questionário aberto (veja detalhes da pesquisa em SOUZA, 2010). O objetivo desta etapa foi confrontar os fatores levantados na pesquisa bibliográfica com aqueles apontados pelos auditores. Esta etapa permitiu a confirmação de fatores já apontados pela pesquisa bibliográfica como também revelou outros.

O questionário aberto foi enviado por correio eletrônico (e-mail) para uma amostra constituída por seis auditores de SGQ, em atividade, do setor aeroespacial, reconhecidos pelo International Aerospace Quality Group (IAQG). Três dos seis auditores são qualificados como AEA e outros três, como auditores NBR 15100. Registra-se que no período de realização da pesquisa havia 12 auditores AEA e 14 auditores NBR 15100 no Brasil.
Por se tratar de uma etapa exploratória, seguiram-se as orientações de Godoy (2005) ao priorizar boas práticas de pesquisa qualitativa, quais sejam: registros das etapas do processo de pesquisa, formulação do problema, seleção do participante, notas de campo, transcrição de entrevistas e decisões sobre procedimentos analíticos.

Depois do exame dos resultados, foram criados grandes grupos de influência e os fatores apontados por esta pesquisa foram distribuídos dentro desses grupos. Ao final desta etapa, identificaram-se 22 fatores que influenciam o processo de auditoria.

\subsection{Elaboração do questionário fechado}

Depois que os dados foram analisados e classificados, como foi descrito na etapa anterior, construiu-se um questionário fechado, (SOUZA, 2010), que foi respondido por uma amostra de auditores de SGQ do setor aeroespacial. Este questionário abrange os 22 fatores identificados, sendo que para cada um são realizadas duas perguntas, uma com o objetivo de avaliar a importância do fator e a outra para identificar sua aplicação. Ambas as respostas baseiam-se na percepção do auditor entrevistado.

Para cada questão, utilizou-se a escala de Likert de cinco pontos para avaliar o grau de importância e o grau de aplicação de cada fator. A escala varia de forma decrescente conforme o Quadro 1. Para o nível de importância, a escala varia desde sem importância (1) até extremamente importante (5). Para o nível de aplicação de cada fator, a faixa de variação vai de nada eficaz (1) até extremamente eficaz (5), ou de nenhuma atenção (1) até muitíssima atenção (5), ou ainda de muito baixo (1) até muito alto (5), dependendo da maneira como a questão foi elaborada.

A população da pesquisa fechada é composta por 26 auditores de SGQ do setor aeroespacial no Brasil: 46,1\% deles são auditores AEA e 53,9\% são auditores NBR 15100. A pesquisa obteve 13 questionários respondidos ( 7 auditores AEA e 6 auditores NBR 15100).

\subsection{Tabulação dos resultados da pesquisa}

A tabulação dos resultados é apresentada na Seção 4. Com os valores tabulados é calculada a média dos valores para cada resposta.

Quadro 1. Escala de Likert utilizada no questionário fechado.

\begin{tabular}{|c|l|l|l|l|}
\hline Valor & Nível de importância & \multicolumn{3}{|c|}{ Nível de aplicação } \\
\hline 5 & Extremamente importante & Extremamente eficaz & Muitíssima atenção & Muito alto \\
\hline 4 & Muito importante & Muito eficaz & Muita atenção & Alto \\
\hline 3 & Importante & Eficaz & Atenção & Médio \\
\hline 2 & Pouco importante & Pouco eficaz & Pouca atenção & Baixo \\
\hline 1 & Sem importância & Nada eficaz & Nenhuma atenção & Muito baixo \\
\hline
\end{tabular}

Fonte: elaborado pelos autores (2010). 
Desta forma, é possível calcular a pontuação média do nível de importância para cada fator e a pontuação média do nível de aplicação desse fator. Com isso, é possível determinar a diferença entre estes valores médios, ou seja, o GAP existente entre a importância atribuída ao fator e o nível de aplicação desse fator nas indústrias, segundo a percepção dos auditores.

\section{Resultados e discussões}

Esta seção apresenta e comenta os resultados tanto do questionário aberto quanto do questionário fechado.

\subsection{Resultados do questionário aberto}

O questionário aberto com os auditores e mais a pesquisa bibliográfica identificaram vinte e dois fatores que afetam o processo de auditoria conforme segue:

A tabulação dos resultados das entrevistas foi baseada no significado e nas explicações que os entrevistados atribuem às perguntas formuladas no questionário aberto (veja detalhes da pesquisa em SOUZA, 2010). Para o tratamento dos dados, utilizou-se a técnica de análise de conteúdo (VERGARA, 2005).

Fator 1 - Seleção da equipe de auditoria: para a seleção da equipe de auditoria, deve-se levar em consideração a competência necessária para se alcançar os objetivos da auditoria, inclusive a eventual inclusão de especialista.

Fator 2 - Análise prévia do SGQ da organização: análise crítica da documentação relacionada com o SGQ da organização, antes do início das atividades de auditoria, para se adquirir uma adequada visão geral. Deve-se levar em consideração o tamanho, a natureza e a complexidade da organização.

Fator 3 - Confecção do plano de auditoria: o plano de auditoria inclui informações tais como, objetivo, critério e escopo da auditoria, assim como data, local, duração e sequência das atividades de auditoria no local.

Fator 4 - Relação auditor-dia: é o tempo utilizado na auditoria, calculado como o produto do número de auditores envolvidos na realização da auditoria pelo número de dias utilizados na auditoria. Depende da complexidade do SGQ e da criticidade dos itens sob análise.

Fator 5 - Comunicação durante a auditoria: capacidade de se comunicar com eficácia, ao realizar a auditoria, com os diversos níveis hierárquicos da organização auditada.

Fator 6 - Amostragem: amostragem das informações disponíveis utilizada para coleta de evidências. Atentar ao elemento de incerteza ao se auditar. A amostragem apropriada está diretamente relacionada com a confiança que pode ser atribuída às conclusões da auditoria.
Fator 7 - Abordagem de coleta de evidências: abordagem utilizada para coletar evidências durante a auditoria, tais como entrevistas, observações e análise crítica de documentos.

Fator 8 - Uso do : utilização de formulário que relaciona as questões a serem verificadas na realização da auditoria. Seu uso é obrigatório nas auditorias de terceira parte no setor aeroespacial.

Fator 9 - Abordagem de processo: abordagem utilizada com foco nos processos, tais como, identificação, interação e sua gestão para produzir o resultado planejado da organização e não os requisitos da norma (NBR ISO 9001; NBR 15100).

Fator 10 - Apresentação das constatações e conclusões da auditoria: capacidade do líder da equipe de auditoria de apresentar as constatações e conclusões da auditoria de tal maneira que elas sejam compreendidas e reconhecidas pelo auditado. Preparar, completar e apresentar o relatório de auditoria. E avaliar os fatores que possam afetar a confiabilidade das constatações e conclusões da auditoria.

Fator 11 - Acompanhamento das ações corretivas: forma de acompanhamento de ações corretivas necessárias para o tratamento das eventuais não conformidades identificadas na auditoria, e deve ser verificada a eficácia da ação corretiva.

Fator 12 - Gerenciamento de conflitos: capacidade de prevenir e solucionar conflitos tanto dentro da equipe de auditoria, quanto entre a equipe e o auditado.

Fator 13 - Avaliação do processo de auditoria por parte do auditado: sistemática utilizada para obter as informações relativas à percepção sobre o processo de auditoria.

Fator 14 - Avaliação do processo de auditoria por parte do Organismo de Acreditação: sistemática de avaliação do processo de auditoria realizada pelo Organismo de Acreditação.

Fator 15 - Melhoria do processo de auditoria: conjunto de ações e decisões para a melhoria contínua do processo de auditoria.

Fator 16 - Conhecimento dos requisitos da norma NBR 15100:2004: conhecimento do conjunto de requisitos da norma, principal critério de auditoria do setor aeroespacial, usado como uma referência contra a qual a evidência da auditoria é comparada.

Fator 17 - Conhecimento dos princípios, procedimentos e técnicas de auditoria: conhecimento do conjunto de diretrizes e requisitos para a realização de auditorias, provenientes da NBR ISO 19011 e dos Organismos de Certificação e de Acreditação.

Fator 18 - Conhecimento de características do setor: conhecimentos específicos dos processos, produtos, requisitos e práticas do setor aeroespacial.

Fator 19 - Conhecimento de técnicas da qualidade: conhecimento da terminologia, princípios e ferramentas da qualidade, como FMEA, 5S, Método de solução de problemas. 
Fator 20 - Atributos pessoais do auditor: ética, diplomacia, capacidade de observação, capacidade de percepção, versatilidade, tenacidade e autoconfiança.

Fator 21 - Comprometimento da alta direção: comprometimento das pessoas do mais alto nível hierárquico da empresa auditada com a implementação e a manutenção do sistema de gestão da qualidade.

Fator 22 - Proatividade do auditado: Postura proativa do auditado diante das atividades da auditoria.

Estes fatores podem ser agrupados em três categorias, conforme mostrado no Quadro 2. Estes fatores são identificados como fatores que influenciam, de forma significativa, a auditoria de SGQ no setor aeroespacial, e, portanto, espera-se que tais fatores possuam uma importância relativamente alta. A validação destes fatores como influentes no processo de auditoria será realizada com a aplicação do questionário fechado, no qual serão coletados dados sobre a percepção dos auditores quanto à importância destes fatores.

\subsection{Resultados do questionário fechado}

A análise dos dados é dividida em três partes: Análise do nível de importância dos fatores; Análise do nível de aplicação dos fatores; e Análise das discrepâncias $(G A P)$ entre os níveis de importância e de aplicação. A Tabela 1 apresenta os resultados

Quadro 2. Agrupamento dos fatores em categorias.

\begin{tabular}{|c|l|}
\hline Categoria & \multicolumn{1}{c|}{ Fator } \\
\hline \multirow{3}{*}{ Atividades de auditoria } & Planejamento da auditoria (Fator 1-4) \\
& Realização da auditoria (Fator 5-12) \\
& Verificação da auditoria (Fator 13, 14) \\
& Melhoria da auditoria (Fator 15) \\
\hline \multirow{2}{*}{ Competência do auditor } & Conhecimento (Fator 16-19) \\
& Atributos pessoais (Fator 20) \\
\hline \multirow{2}{*}{ Características do auditado } & Comprometimento da alta direção (Fator 21) \\
& Proatividade do auditado (Fator 22) \\
\hline
\end{tabular}

Fonte: elaborado pelos autores (2010).

Tabela 1. Pontuação média encontrada.

\begin{tabular}{|c|c|c|c|c|}
\hline Fator & Descrição & $\begin{array}{c}\text { Nível de } \\
\text { importância }\end{array}$ & $\begin{array}{l}\text { Nível de } \\
\text { aplicação }\end{array}$ & GAP \\
\hline Fator 1 & Seleção da equipe de auditoria & 4,69 & 2,69 & 2,00 \\
\hline Fator 2 & Análise prévia do SGQ da organização & 4,08 & 2,38 & 1,69 \\
\hline Fator 3 & Confecção do plano de auditoria & 4,15 & 2,69 & 1,46 \\
\hline Fator 4 & Relação auditor-dia & 3,46 & 3,77 & $-0,31$ \\
\hline Fator 5 & Comunicação durante a auditoria & 4,77 & 3,08 & 1,69 \\
\hline Fator 6 & Amostragem & 4,15 & 3,23 & 0,92 \\
\hline Fator 7 & Abordagem de coleta de evidências & 4,46 & 3,31 & 1,15 \\
\hline Fator 8 & Uso de check list & 3,15 & 2,85 & 0,31 \\
\hline Fator 9 & Abordagem de processo & 4,31 & 2,85 & 1,46 \\
\hline Fator 10 & Apresentação das constatações e conclusões da auditoria & 4,23 & 3,38 & 0,85 \\
\hline Fator 11 & Acompanhamento das ações corretivas & 4,38 & 2,92 & 1,46 \\
\hline Fator 12 & Gerenciamento de conflitos & 4,62 & 3,08 & 1,54 \\
\hline Fator 13 & Avaliação do processo de auditoria por parte do auditado & 3,85 & 2,69 & 1,15 \\
\hline Fator 14 & $\begin{array}{l}\text { Avaliação do processo de auditoria por parte do } \\
\text { Organismo de Acreditação }\end{array}$ & 4,00 & 2,38 & 1,62 \\
\hline Fator 15 & Melhoria do processo de auditoria & 4,62 & 2,77 & 1,85 \\
\hline Fator 16 & Conhecimento dos requisitos da norma NBR 15100:2004 & 4,92 & 3,85 & 1,08 \\
\hline Fator 17 & $\begin{array}{l}\text { Conhecimento dos princípios, procedimentos e técnicas } \\
\text { de auditoria }\end{array}$ & 4,46 & 3,31 & 1,15 \\
\hline Fator 18 & Conhecimento das características específicas do setor & 4,54 & 3,62 & 0,92 \\
\hline Fator 19 & Conhecimento das técnicas relacionadas com qualidade & 3,85 & 3,00 & 0,85 \\
\hline Fator 20 & Atributos pessoais do auditor & 4,46 & 3,62 & 0,85 \\
\hline Fator 21 & Comprometimento da alta direção & 4,77 & 2,85 & 1,92 \\
\hline Fator 22 & Proatividade do auditado & 4,00 & 3,00 & 1,00 \\
\hline
\end{tabular}


obtidos na pesquisa com questionário fechado tratados conforme o item 3.2.

\subsubsection{Análise do nível de importância dos fatores}

Esta seção analisa as pontuações médias encontradas para o nível de importância de cada fator. Os dados da Tabela 1, em ordem decrescente de nível de importância, estão apresentados na Tabela 2.

Observando-se a Tabela 2 constata-se que sete fatores estão classificados como "extremamente importante"; treze estão classificados como "muito importante" e dois como "importante", segundo a escala apresentada no Quadro 1.

$\mathrm{O}$ fator identificado na pesquisa com o maior nível de importância na ótica dos auditores é o Fator 16 - Conhecimento dos requisitos da norma NBR 15100:2004. Isto significa que o conhecimento, por parte do auditor, dos requisitos determinados na norma utilizada como referência na auditoria de certificação é o principal fator para o sucesso de uma auditoria, na visão dos auditores de SGQ do setor aeroespacial.

Na segunda posição, empataram o Fator 5 Comunicação durante a auditoria e o Fator 21
- Comprometimento da alta direção. Segundo a pesquisa, a capacidade do auditor de se comunicar com os diversos níveis hierárquicos da organização é um fator extremamente importante para o sucesso da auditoria, assim como o comprometimento da alta direção do auditado. Isso evidencia que o sucesso da auditoria depende do auditor e do auditado (alta direção).

O quarto fator em nível de importância é o Fator 1 - Seleção da equipe de auditoria. Este fator está ligado ao planejamento da auditoria e abrange a seleção de determinadas competências para a realização de auditoria.

Empataram na quinta posição o Fator 12 Gerenciamento de conflitos e o Fator 15 - Melhoria do processo de auditoria. Isto significa que a capacidade do auditor de prevenir e solucionar conflitos ao longo da auditoria é um fator classificado como extremamente importante, assim como as ações que visam a melhoria contínua do processo de auditoria.

\subsubsection{Análise do nível de aplicação dos fatores}

Esta seção analisa as médias encontradas para o nível de aplicação do fator, ou seja, analisa como os fatores que afetam o processo de auditoria de SGQ

Tabela 2. Ordenação da Tabela 1 pelo nível de importância do fator.

\begin{tabular}{|c|c|c|c|c|}
\hline Fator & Descrição & $\begin{array}{c}\text { Nível de } \\
\text { importância }\end{array}$ & $\begin{array}{l}\text { Nível de } \\
\text { aplicação }\end{array}$ & GAP \\
\hline Fator 16 & Conhecimento dos requisitos da norma NBR 15100:2004 & 4,92 & 3,85 & 1,08 \\
\hline Fator 5 & Comunicação durante a auditoria & 4,77 & 3,08 & 1,69 \\
\hline Fator 21 & Comprometimento da alta direção & 4,77 & 2,85 & 1,92 \\
\hline Fator 1 & Seleção da equipe de auditoria & 4,69 & 2,69 & 2,00 \\
\hline Fator 12 & Gerenciamento de conflitos & 4,62 & 3,08 & 1,54 \\
\hline Fator 15 & Melhoria do processo de auditoria & 4,62 & 2,77 & 1,85 \\
\hline Fator 18 & Conhecimento das características específicas do setor & 4,54 & 3,62 & 0,92 \\
\hline Fator 7 & Abordagem de coleta de evidências & 4,46 & 3,31 & 1,15 \\
\hline Fator 17 & $\begin{array}{l}\text { Conhecimento dos princípios, procedimentos e técnicas de } \\
\text { auditoria }\end{array}$ & 4,46 & 3,31 & 1,15 \\
\hline Fator 20 & Atributos pessoais do auditor & 4,46 & 3,62 & 0,85 \\
\hline Fator 11 & Acompanhamento das ações corretivas & 4,38 & 2,92 & 1,46 \\
\hline Fator 9 & Abordagem de processo & 4,31 & 2,85 & 1,46 \\
\hline Fator 10 & Apresentação das constatações e conclusões da auditoria & 4,23 & 3,38 & 0,85 \\
\hline Fator 3 & Confecção do plano de auditoria & 4,15 & 2,69 & 1,46 \\
\hline Fator 6 & Amostragem & 4,15 & 3,23 & 0,92 \\
\hline Fator 2 & Análise prévia do SGQ da organização & 4,08 & 2,38 & 1,69 \\
\hline Fator 14 & $\begin{array}{l}\text { Avaliação do processo de auditoria por parte do Organismo } \\
\text { de Acreditação }\end{array}$ & 4,00 & 2,38 & 1,62 \\
\hline Fator 22 & Proatividade do auditado & 4,00 & 3,00 & 1,00 \\
\hline Fator 13 & Avaliação do processo de auditoria por parte do auditado & 3,85 & 2,69 & 1,15 \\
\hline Fator 19 & Conhecimento das técnicas relacionadas com qualidade & 3,85 & 3,00 & 0,85 \\
\hline Fator 4 & Relação auditor-dia & 3,46 & 3,77 & $-0,31$ \\
\hline Fator 8 & Uso de check list & 3,15 & 2,85 & 0,31 \\
\hline
\end{tabular}


no setor aeroespacial estão sendo aplicados, na prática, segundo a percepção dos auditores de SGQ deste setor. A identificação do nível de aplicação é especialmente importante para se chegar aos GAPS entre a importância e a aplicação do fator, que serão analisados na seção seguinte. A Tabela 3 apresenta os dados da Tabela 1 ordenados em ordem decrescente pelo Nível de Aplicação.

Observando-se a Tabela 3, verifica-se que as médias para o nível de aplicação dos fatores variam de 2,38 a 3,85 . Se for comparada com a variação do nível de importância $(3,15$ a 4,92), percebe-se uma considerável discrepância (ou $G A P$ ) entre a importância atribuída aos fatores e como estão sendo aplicados na prática.

O fator com maior média para o nível de aplicação é o Fator 16 - Conhecimento dos requisitos da norma NBR 15100:2004. Este resultado é positivo, pois o fator identificado como mais importante para o sucesso da auditoria, também é o fator que vem sendo mais bem aplicado, na percepção dos auditores.

O segundo fator com maior média para nível de aplicação é o Fator 4 - Relação auditor-dia, o que indica que, na percepção dos auditores entrevistados, a relação quantidade de auditor e tempo utilizados na realização das auditorias vem sendo bem aplicada.
Embora este fator tenha se destacado como a segunda maior média para nível de aplicação, ele é classificado como o penúltimo fator em nível de importância.

Na terceira posição empataram dois fatores: o Fator 18 - Conhecimento das características específicas do setor e o Fator 20 - Atributos pessoais do auditor. Na percepção dos participantes da pesquisa, os auditores possuem um alto nível de conhecimento de processos, produtos, requisitos e práticas específicos do setor aeroespacial. Da mesma forma, os participantes da pesquisa percebem que é dada muita atenção para os atributos pessoais do auditor, como ética, diplomacia, capacidade de percepção, versatilidade, tenacidade e autoconfiança.

A quinta maior média é referente ao Fator 10 - Apresentação das constatações e conclusões da auditoria. Isto significa que as constatações e conclusões vêm sendo apresentadas, na reunião de encerramento, de forma que sejam compreendidas e reconhecidas pelo auditado.

Esta análise também permite destacar que, entre os cinco fatores que se destacaram pela boa aplicação, apenas um deles (o Fator 16 - Conhecimento dos requisitos da norma NBR 15100:2004) está entre aqueles cujo nível de importância foi classificado como "extremamente importante".

Tabela 3. Ordenação da Tabela 1 pelo nível de aplicação do fator.

\begin{tabular}{|c|c|c|c|c|}
\hline Fator & Descrição & $\begin{array}{l}\text { Nível de } \\
\text { importância }\end{array}$ & $\begin{array}{l}\text { Nível de } \\
\text { aplicação }\end{array}$ & GAP \\
\hline Fator 16 & Conhecimento dos requisitos da norma NBR 15100:2004 & 4,92 & 3,85 & 1,08 \\
\hline Fator 4 & Relação auditor-dia & 3,46 & 3,77 & $-0,31$ \\
\hline Fator 18 & Conhecimento das características específicas do setor & 4,54 & 3,62 & 0,92 \\
\hline Fator 20 & Atributos pessoais do auditor & 4,46 & 3,62 & 0,85 \\
\hline Fator 10 & Apresentação das constatações e conclusões da auditoria & 4,23 & 3,38 & 0,85 \\
\hline Fator 7 & Abordagem de coleta de evidências & 4,46 & 3,31 & 1,15 \\
\hline Fator 17 & $\begin{array}{l}\text { Conhecimento dos princípios, procedimentos e técnicas de } \\
\text { auditoria }\end{array}$ & 4,46 & 3,31 & 1,15 \\
\hline Fator 6 & Amostragem & 4,15 & 3,23 & 0,92 \\
\hline Fator 5 & Comunicação durante a auditoria & 4,77 & 3,08 & 1,69 \\
\hline Fator 12 & Gerenciamento de conflitos & 4,62 & 3,08 & 1,54 \\
\hline Fator 19 & Conhecimento das técnicas relacionadas com qualidade & 3,85 & 3,00 & 0,85 \\
\hline Fator 22 & Proatividade do auditado & 4,00 & 3,00 & 1,00 \\
\hline Fator 11 & Acompanhamento das ações corretivas & 4,38 & 2,92 & 1,46 \\
\hline Fator 8 & Uso de check list & 3,15 & 2,85 & 0,31 \\
\hline Fator 9 & Abordagem de processo & 4,31 & 2,85 & 1,46 \\
\hline Fator 21 & Comprometimento da alta direção & 4,77 & 2,85 & 1,92 \\
\hline Fator 15 & Melhoria do processo de auditoria & 4,62 & 2,77 & 1,85 \\
\hline Fator 1 & Seleção da equipe de auditoria & 4,69 & 2,69 & 2,00 \\
\hline Fator 3 & Confecção do plano de auditoria & 4,15 & 2,69 & 1,46 \\
\hline Fator 13 & Avaliação do processo de auditoria por parte do auditado & 3,85 & 2,69 & 1,15 \\
\hline Fator 2 & Análise prévia do SGQ da organização & 4,08 & 2,38 & 1,69 \\
\hline Fator 14 & $\begin{array}{l}\text { Avaliação do processo de auditoria por parte do Organismo } \\
\text { de Acreditação }\end{array}$ & 4,00 & 2,38 & 1,62 \\
\hline
\end{tabular}




\subsubsection{Análise das discrepâncias (GAP)}

Nesta pesquisa, GAP foi definido como a diferença entre a importância do fator e sua aplicação na prática. A Tabela 4 apresenta os dados da Tabela 1 ordenados, de forma decrescente, pelo GAP, com os respectivos valores de significância para o teste de hipóteses que compara a diferença entre o nível de importância e o nível de aplicação dos fatores na prática.

Para fins de análise, considerou-se que as diferenças significativas, do ponto de vista estatístico, são aquelas para as quais o nível de significância é menor de que $3 \%$.

$\mathrm{O}$ fator com maior potencial de melhoria no processo de auditoria é o Fator 1 - Seleção da equipe de auditoria, que apresenta o maior GAP. Este resultado indica que deve ser dada maior atenção, por parte daqueles que realizam o planejamento da auditoria, às competências necessárias para os auditores selecionados para a realização da auditoria.

$\mathrm{O}$ segundo fator com maior potencial de melhoria identificado na pesquisa é O Fator 21
- Comprometimento da alta direção. O que mostra que, na percepção dos auditores, o comprometimento da alta direção das organizações auditadas no que diz respeito à implementação e manutenção do SGQ precisa melhorar para que a auditoria alcance seus melhores resultados.

O Fator 15 - Melhoria do processo de auditoria é o terceiro fator com maior GAP. Este fator corresponde às ações e decisões tomadas para melhorar continuamente o processo de auditoria e pode ser entendido como parte da última etapa do ciclo PDCA. Observa-se que ações e decisões para melhorar a auditoria dependem fundamentalmente de medições, monitoramentos e avaliações realizadas sobre o processo de auditoria, e, desta forma, existem dois outros fatores identificados na pesquisa, que estão diretamente relacionados com isso: o Fator 13 - Avaliação do processo de auditoria por parte do auditado e o Fator 14 - Avaliação do processo de auditoria por parte do Organismo de Acreditação. Estes dois fatores influenciam a melhoria da auditoria, pois fornecem as informações para tais

Tabela 4. Ordenação da Tabela 1 pelo GAP.

\begin{tabular}{|c|c|c|c|c|c|}
\hline Fator & Descrição & $\begin{array}{c}\text { Nível de } \\
\text { importância }\end{array}$ & $\begin{array}{c}\text { Nível de } \\
\text { aplicação }\end{array}$ & GAP & $\begin{array}{c}\text { p-Valor } \\
(\%)\end{array}$ \\
\hline Fator 1 & Seleção da equipe de auditoria & 4,69 & 2,69 & 2,00 & 0,0 \\
\hline Fator 21 & Comprometimento da alta direção & 4,77 & 2,85 & 1,92 & 0,0 \\
\hline Fator 15 & Melhoria do processo de auditoria & 4,62 & 2,77 & 1,85 & 0,0 \\
\hline Fator 2 & Análise prévia do SGQ da organização & 4,08 & 2,38 & 1,70 & 0,0 \\
\hline Fator 5 & Comunicação durante a auditoria & 4,77 & 3,08 & 1,69 & 0,0 \\
\hline Fator 14 & $\begin{array}{l}\text { Avaliação do processo de auditoria por parte do } \\
\text { Organismo de Acreditação }\end{array}$ & 4,00 & 2,38 & 1,62 & 0,0 \\
\hline Fator 12 & Gerenciamento do plano de auditoria & 4,62 & 3,08 & 1,54 & 0,0 \\
\hline Fator 3 & Confecção do plano de auditoria & 4,15 & 2,69 & 1,46 & 0,0 \\
\hline Fator 9 & Abordagem de processo & 4,31 & 2,85 & 1,46 & 0,0 \\
\hline Fator 11 & Acompanhamento das ações corretivas & 4,38 & 2,92 & 1,46 & 0,0 \\
\hline Fator 7 & Abordagem de coleta de evidências & 4,46 & 3,31 & 1,15 & 0,0 \\
\hline Fator 13 & $\begin{array}{l}\text { Avaliação do processo de auditoria por parte do } \\
\text { auditado }\end{array}$ & 3,85 & 2,69 & 1,16 & 0,2 \\
\hline Fator 17 & $\begin{array}{l}\text { Conhecimento dos princípios, procedimentos e } \\
\text { técnicas de auditoria }\end{array}$ & 4,46 & 3,31 & 1,15 & 0,1 \\
\hline Fator 16 & $\begin{array}{l}\text { Conhecimento dos requisitos da norma NBR } \\
\text { 15100:2004 }\end{array}$ & 4,92 & 3,85 & 1,07 & 0,0 \\
\hline Fator 22 & Proatividade do auditado & 4,00 & 3,00 & 1,00 & 0,5 \\
\hline Fator 6 & Amostragem & 4,15 & 3,23 & 0,92 & 0,0 \\
\hline Fator 18 & $\begin{array}{l}\text { Conhecimento das características específicas do } \\
\text { setor }\end{array}$ & 4,54 & 3,62 & 0,92 & 0,3 \\
\hline Fator 10 & $\begin{array}{l}\text { Apresentação das constatações e conclusões da } \\
\text { auditoria }\end{array}$ & 4,23 & 3,38 & 0,85 & 0,8 \\
\hline Fator 19 & $\begin{array}{l}\text { Conhecimento das técnicas relacionadas com } \\
\text { qualidade }\end{array}$ & 3,85 & 3,00 & 0,85 & 2,6 \\
\hline Fator 20 & Atributos pessoais do auditor & 4,46 & 3,62 & 0,84 & 2,1 \\
\hline Fator 8 & Uso de check list & 3,15 & 2,85 & 0,30 & 33,8 \\
\hline Fator 4 & Relação auditor-dia & 3,46 & 3,77 & $-0,31$ & 27,0 \\
\hline
\end{tabular}


ações e decisões de melhoria. A análise do nível de aplicação desses dois fatores, discutido na seção anterior, mostra que esses fatores estão entre aqueles com as piores pontuações.

O Fator 2 - Análise prévia do SGQ da organização é o quarto com maior $G A P$ e o segundo fator com o pior resultado para a aplicação, mostrando que existe potencial significativo de melhoria na fase de planejamento, momento em que os auditores analisam criticamente a documentação do SGQ da organização com o objetivo de adquirir uma visão adequada dos produtos e processos desta organização.

O Fator 5 - Comunicação durante a auditoria tem o quinto maior $G A P$, indicando um grande potencial de melhoria na capacidade de comunicação dos auditores ao conduzirem as auditorias.

Observa-se que não há evidências estatísticas que contradigam que o nível de aplicação é igual ao nível de importância para os A Relação Auditor-dia (Fator 4) e uso de Check lists (Fator 8). Nota-se que ambos os fatores são requisitos prescritos na própria norma, de forma que é natural que o nível de importância e o nível de aplicação dos fatores na prática tenham valores próximos.

Apenas Análise prévia do SGQ da organização (Fator 2) não está entre os fatores identificados como "mais importantes". Este resultado é de significativa importância para esta pesquisa, pois demonstra que estes fatores devem ser tratados de forma diferenciada para se alcançar o sucesso da auditoria, pois além de serem os que mais afetam a auditoria, na prática, estes fatores possuem um grande potencial de melhoria.

\section{Conclusões}

Este estudo parte da premissa de que a auditoria de certificação de SGQ é uma importante ferramenta para a competitividade das empresas, e que ao mesmo tempo em que a quantidade desta auditoria vem crescendo em todo o mundo, as críticas com relação à sua eficácia também estão aumentando. Este trabalho identificou oportunidades importantes de melhoria do processo de auditoria de SGQ no setor aeroespacial.

Inicialmente foram identificados os principais fatores que afetam o processo de auditoria de SGQ no setor aeroespacial, por meio da pesquisa bibliográfica juntamente com a pesquisa exploratória. Estes fatores, num total de vinte e dois, são apresentados na seção 4.1. Assim, o objetivo específico de se identificar tais fatores foi alcançado.

Além da identificação dos principais fatores que afetam o processo de auditoria, este estudo verificou a percepção dos auditores de SGQ do setor aeroespacial sobre a importância desses fatores e como estão sendo aplicados, na prática. Com isso, a pesquisa identificou os fatores mais importantes para o sucesso da auditoria, e sua aplicação na prática. Desta forma, o objetivo específico de verificar a percepção dos auditores quanto à importância e aplicação dos fatores foi alcançado. Esta verificação foi apresentada na seção 4.2.

A percepção dos auditores de SGQ do setor aeroespacial mostrou que existem consideráveis discrepâncias (GAPS) entre a importância dada ao fator e sua aplicação na prática. É justamente onde estão os maiores GAPS que se encontram as maiores oportunidades de melhoria no processo de auditoria. Assim, o objetivo específico de analisar a relação existente entre a percepção dos auditores quanto ao nível de importância e de aplicação dos fatores foi alcançado. Esta análise também se encontra na seção 4.2 .

Um dos resultados mais importantes da pesquisa é que a maioria dos fatores identificados com os maiores GAPS, ou seja, a maioria dos fatores com maiores oportunidades de melhoria estão entre aqueles considerados como "muito importante" ou "extremamente importante". Isso alavanca significativamente os resultados, pois prioriza aqueles fatores que devem ser trabalhados com maior atenção para se buscar a melhoria do processo de auditoria no setor aeroespacial.

O fato de se buscar a percepção dos auditores da qualidade do setor aeroespacial é um ponto positivo da pesquisa, pois eles estão diretamente envolvidos no processo e são os maiores especialistas no assunto, visto que a quantidade de auditoria de que o auditor participa ao longo do ano é significativamente maior do que as outras partes envolvidas na auditoria, como a organização auditada ou o cliente da auditoria.

Portanto, o objetivo principal desta pesquisa foi atingido, uma vez que o processo de auditoria de SGQ no setor aeroespacial brasileiro foi analisado e oportunidades de melhoria deste processo foram identificadas.

Ao analisar o processo de auditoria de certificação de SGQ, por meio do desdobramento deste processo em diversos fatores importantes, esta pesquisa contribui com o tema "auditoria de sistema de gestão da qualidade". Na prática, os resultados desta pesquisa também podem contribuir na capacitação dos auditores de SGQ, e para orientar os gestores em suas decisões relacionadas ao processo de auditoria de SGQ.

Indica-se como trabalho futuro, aprofundar a análise dos resultados por meio do uso da técnica Delphi com a população de auditores do setor aeroespacial e replicar o estudo em outros setores, para analisar diferenças particulares entre setores distintos.

\section{Referências}

ASSOCIAÇÃO BRASILEIRA DE NORMAS TÉCNICAS - ABNT. NBR 15100: Sistema de qualidade: aeroespacial: modelo para garantia da qualidade em projeto, desenvolvimento, produção, instalação e serviços associados. Rio de Janeiro: ABNT, 2004. 
ASSOCIAÇÃO BRASILEIRA DE NORMAS TÉCNICAS - ABNT. NBR ISO 19011: diretrizes para auditorias de sistema de gestão da qualidade e/ou ambiental. Rio de Janeiro: ABNT, 2002.

ASSOCIAÇÃO BRASILEIRA DE NORMAS TÉCNICAS - ABNT. NBR ISO 9001: sistemas de gestão da qualidade: requisitos. Rio de Janeiro: ABNT, 2008.

ASSOCIAÇÃO BRASILEIRA DE NORMAS TÉCNICAS - ABNT. NBR ISO/IEC 17000: avaliação de conformidade: vocabulário e princípios gerais. Rio de Janeiro: ABNT, 2005.

ASSOCIAÇÃO BRASILEIRA DE NORMAS TÉCNICAS - ABNT. NBR ISO/IEC 17021: avaliação de conformidade: requisitos para organismos que fornecem auditoria e certificação de sistemas de gestão. Rio de Janeiro: ABNT, 2007.

BECKMERHAGEN, I. A. et al. On the Effectiveness of Quality Management System Audits. The TQM Magazine, v. 16, n. 1, p. 14-25, 2004.

COSTA, A. F. Processo de acreditação de organismos de certificação utilizado pelo INMETRO: um estudo comparativo com as organizações congêneres de diversos países. 2006. 92 f. Dissertação (Mestrado em Sistemas de Gestão) - Universidade Federal Fluminense, Niterói, 2006.

GODOY, A. S. Refletindo sobre critérios de qualidade da pesquisa qualitativa. Revista Eletrônica de Gestão Organizacional, v. 3, n. 2, 2005. Disponível em: <http:// www.gestaoorg.dca.ufpe.br/>. Acesso em: 12 set. 2011.

INSTITUTO NACIONAL DE METROLOGIA, QUALIDADE E TECNOLOGIA - INMETRO. NIT-DICOR-062: requisitos para qualificação de auditores de sistema de gestão da qualidade NBR 15100, rev. 06. Disponível em: <http://www.inmetro.gov.br/ Sidoq/Arquivos/DICOR/NIT/NIT-DICOR-60_06.pdf>. Acesso em: 12 jan. 2010.

INTERNATIONAL AEROSPACE QUALITY GROUP - IAQG. Disponível em: <http://www.iaqg. sae.org/iaqg>. Acesso em: 10 jan. 2010.
INTERNATIONAL ORGANIZATION FOR STANDARDIZATION - ISO. The ISO survey - 2008. Disponível em: <http://www.iso.org >. Acesso em: 08 fev. 2010.

KAZILIÛNAS, A. Problems of auditing using quality management systems for sustainable development of organizations. Technological and Economic Development of Economy, v. 14, n. 1, p. 64-75, 2008.

MIRANDA, A. R. A. et al. A influência da certificação ISO 9001 no ambiente, sob a perspectiva dos clientes internos e externos. In: ENCONTRO NACIONAL DE ENGENHARIA DE PRODUÇÃO - ENEGEP, 26., 2006, Fortaleza. Anais... Fortaleza: ABEPRO, 2006.

PISKAR, F. Quality audits and their value added. International Journal of Services and Standards, v. 2, n. 1, p. 69-83, 2006.

POKSINSKA, B. et al. From compliance to value-added auditing - experiences from Swedish ISO 9001:2000 certified organizations. Total Quality Management \& Business Excellence, v. 17, n. 7, p. 879-892, 2006.

RUSSELL, J. P. Know and follow ISO 19011's auditing principles. Quality Progress, v. 40, n. 2, p. 29-34, 2007.

SOUZA, L. P. Análise Crítica do Processo de Auditoria de Sistema de Gestão da Qualidade no Setor Aeroespacial. 2010. 94 f. Dissertação (Mestrado em Engenharia Mecânica)-Universidade de Taubaté, Taubaté, 2010. Disponível em: <www.unitau.br/ cursos/pos-graduacao/mestrado/engenharia-mecanica/ dissertacao/2010/Luciano\%20Pereira\%20de\%Souza. pdf $>$.

TERLAACK, A.; KING, A. A. The effect of certification with ISO 9001 quality management standard: a signaling approach. Jornal of Economic Behavior \& Organization, v. 60, n. 1, p. 579-602, 2006.

VERGARA, C. S. Métodos de pesquisa em administração. São Paulo: Atlas, 2005.

WIELE, T. V. et al. Perceptions about the ISO 9000 (2000) quality system standard revision and its value: the Dutch experience. International Journal of Quality \& Reability Management, v. 22, n. 2, p. 101-119, 2004. 